\title{
BMJ Open Prediction of fetal loss in Chinese pregnant patients with systemic lupus erythematosus: a retrospective cohort study
}

\author{
Jiayue Wu, ${ }^{1,2,3}$ Wei-Hong Zhang, ${ }^{3,4}$ Jinghang Ma, ${ }^{1,2}$ Chunde Bao, ${ }^{5,6}$ Jinlin Liu, ${ }^{7}$ \\ Wen $\mathrm{Di}^{1,2}$
}

To cite: Wu J, Zhang W-H, Ma J, et al. Prediction of fetal loss in Chinese pregnant patients with systemic lupus erythematosus: a retrospective cohort study. BMJ Open 2019;9:e023849. doi:10.1136/ bmjopen-2018-023849

- Prepublication history and additional material for this paper are available online. To view these files, please visit the journal online (http://dx.doi. org/10.1136/bmjopen-2018023849).

W-HZ and WD contributed equally.

Received 30 April 2018 Revised 12 November 2018 Accepted 20 December 2018

D Check for updates

(c) Author(s) (or their employer(s)) 2019. Re-use permitted under CC BY-NC. No commercial re-use. See rights and permissions. Published by BMJ.

For numbered affiliations see end of article.

\section{Correspondence to} DrWen Di; diwen163@163.com and Dr Wei-Hong Zhang; weihong.zhang@ugent.be

\section{ABSTRACT}

Objective To develop a predictive model for fetal loss in women with systemic lupus erythematosus (SLE).

Design A retrospective cohort study.

Setting Data were collected in a tertiary medical centre, located in Shanghai, China, from September 2011 to May 2017.

Participants 338 pregnancies with SLE were analysed retrospectively. Cases of multiple pregnancy and those in which artificial abortion was performed for personal reasons were excluded.

Primary outcome measures Fetal loss was the primary outcome. A stepwise regression to identify the predictors related to the fetal loss and coefficient $B$ of each variable was used to develop a predictive model and make a corresponding risk classification. The Hosmer-Lemeshow test, Omnibus test and area under the receiver-operating characteristic curve (AUC) were used to assess the goodness-of-fit and discrimination of the predictive model. A 10-fold cross validation was used to assess the model for overfitting.

Results Unplanned pregnancies (OR 2.84, 95\% Cl 1.12 to 7.22 ), $\mathrm{C}_{3}$ hypocomplementemia (OR 5.46 , $95 \% \mathrm{Cl} 2.30$ to 12.97 ) and 24 hour-urinary protein level ( $0.3 \leq$ protein $<1.0 \mathrm{~g} / 24$ hours: OR $2.10,95 \% \mathrm{Cl} 0.63$ to 6.95; protein $\geq 1.0 \mathrm{~g} / 24$ hours: OR $5.89,95 \% \mathrm{Cl} 2.30$ to 15.06) were selected by the stepwise regression. The Hosmer-Lemeshow test resulted in $p=0.325$; the Omnibus test resulted in $\mathrm{p}<0.001$ and the AUC was $0.829(95 \% \mathrm{Cl}$ 0.744 to 0.91 ) in the regression model. The corresponding risk score classification was divided into low risk (0-3) and high risk groups (>3), with a sensitivity of $60.5 \%$, a specificity of $93.3 \%$, positive likelihood ratio of 9.03 and negative likelihood ratio of 0.42 .

Conclusions A predictive model for fetal loss in women with SLE was developed using the timing of conception, $\mathrm{C}_{3}$ complement and 24 hour-urinary protein level. This model may help clinicians in identifying women with high risk pregnancies, thereby carrying out monitoring or/and interventions for improving fetal outcomes.

\section{INTRODUCTION}

Systemic lupus erythematosus (SLE) is a multisystem autoimmune disease, and it primarily affects women of childbearing
Strengths and limitations of this study

- This study developed a prediction model and risk score classification for systemic lupus erythematosus fetal loss.

- The model of prediction has a good fit and discrimination, as does the risk score classification, indicating a higher predictive value.

- The risk score classification is clinically practical, as the model is simple and the variables included are routinely collected during the first antenatal care visit.

- The limitation of this model was the development and validation process applied the same cohort. Although 10 -fold cross-validation was performed and had a good result, it still cannot assess the generalisability of this model.

age. Women with SLE have normal fertility rate, ${ }^{1}$ and pregnancy is therefore a frequent subject of interest to these patients. Adverse pregnancy outcomes are common in this population, with an estimated $20 \%$ ending in miscarriage and $3 \%$ in stillbirth. ${ }^{2}$ As the treatment of SLE has greatly improved over the past two decades, the majority of SLE women can carry out a live birth delivery. ${ }^{3}$ Prediction of pregnancy outcomes for patients with SLE can significantly contribute towards providing effective preconception consultation and treatment as well as prevent adverse pregnancy outcome and complications. Advice about safety and timing of conception requires identification of clinical and laboratory variables that predict fetal loss and other adverse pregnancy outcomes. ${ }^{4}$ While numerous studies have identified risk factors for fetal loss in pregnant women with SLE, such as lupus nephritis, ${ }^{5-7}$ SLE activity during 6 months before pregnancy, ${ }^{8}$ low complement levels, ${ }^{9}$ antiphospholipid syndrome, anti-SSA/Ro antibodies, thrombocytopenia ${ }^{10}$ 
and many other factors have been introduced in previous studies, ${ }^{11-17}$ results varied among studies. The numerous risk factors and the complicated relationships among these factors necessitate the development of a clinical prediction model. It is essential and helpful if the clinician is able to predict the risk of fetal loss in pregnant patients with SLE in the early stages of gestation, which can allow special monitoring and treatment as early as possible. Application of prediction model in pregnancy has been studied for years ${ }^{1518}$; However, very few studies ${ }^{419}$ have proposed such a predictive model or risk score in predicting the fetal loss risk in SLE women. We therefore conducted a retrospective study at a tertiary hospital in Shanghai, China and sought to identify clinical and laboratory predictors for fetal loss in pregnant patients with SLE to develop a risk score and classification.

\section{MATERIALS AND METHODS}

\section{Study design and population}

This was a retrospective, observational study performed at Ren Ji Hospital, Shanghai Jiao Tong University School of Medicine, Shanghai, China. Our study population included all the pregnant women treated for SLE between September 2011 and May 2017. Patients with multiple gestations and those who underwent artificial abortions due to personal reasons were excluded from this analysis. A total of 338 pregnancies with SLE were included in the final analysis. SLE was diagnosed according to the revised criteria for classification of SLE developed by the American College of Rheumatology. ${ }^{20}$

\section{Variables of interest}

Baseline characteristics of interest included maternal age at delivery, region, parity, the history of spontaneous or therapeutic abortions. Regions were categorised as either urban or rural areas. Clinical information included SLE clinical features and laboratory information from the first antenatal care records (16-20 weeks). Comorbidities included a pre-pregnancy diagnosis of hypertension or diabetes. No women in the study population were smokers or drinkers, so lifestyle (eg, smoking and drinking) was not analysed in this study. With respect to different timings of conception, patients were divided into a planned pregnancy group, which consisted of patients who had controlled SLE or were in remission for more than 6 months prior to conception and an unplanned pregnancy group, which consisted of patients with active lupus disease before conception or new onset SLE during pregnancy. SLE Disease Activity Index 2000 (SLEDAI-2K) was used as a valid measure of disease activity and SLEDAI-2K $>4$ was defined as an active stage of SLE. ${ }^{21}$ Laboratory data included a complete blood count, urinalysis, serum albumin, 24hours urinary protein, complement $3\left(\mathrm{C}_{3}\right)$, complement $4\left(\mathrm{C}_{4}\right)$, antinuclear antibodies, anti-dsDNA antibodies (anti-dsDNA), anti-Smith antibodies(anti-Sm), anti-SSA/Ro antibodies, anti-SSB/ La antibodies and antiphospholipid (aPL) antibodies, which included anticardiolipin antibodies (aCL), anti-2-glycoprotein I antibodies (anti- $\beta 2 \mathrm{GPI}$ ) and lupus anticoagulant (LA). All laboratory tests were performed using standardised methods.

The gestational age of fetal loss or delivery and birth weight were also recorded. Abstracted fetal outcomes and definitions were as follows:

- Live birth: the birth of a living child.

- Preterm birth: delivery prior to 37 weeks of gestation.

- Low birth weight (LBW): birth weight $\leq 2500 \mathrm{~g}$, regardless of gestational age and circumstances. ${ }^{22}$ LBW infants were divided into term LBW and preterm LBW based on their gestational age.

- Fetal loss: included spontaneous abortions, therapeutic abortions, stillbirths or intrauterine fetal deaths and neonatal deaths. Additional definitions were as follows:

- Spontaneous abortion: spontaneous termination of pregnancy prior to 28 weeks of gestation.

- Therapeutic abortion: abortion for therapeutic reasons because the pregnancy might be a threat to maternal health, such as life-threatening SLE flare $^{23}$ or other severe obstetric complications, including severe thrombocytopaenia or HELLP (haemolysis, elevated liver enzymes, and low platelet count) syndrome and so on.

- Stillbirth or intrauterine fetal death: any baby born without signs of life at greater than or equal to 28 completed weeks of gestation. ${ }^{24}$

- Neonatal death: death of a live-born baby within the first 28 days of life. ${ }^{25}$

\section{Patient and public involvement}

Patients and the public were not involved in the design and conception of the study and there are no plans to disseminate the results to patients.

\section{Statistical analysis}

Descriptive data are shown as the mean $\pm \mathrm{SD}$ or as a frequency. Categorical variables were analysed using $\chi^{2}$ or Fisher's exact probability tests as appropriate. Continuous variables were analysed using Student's t test where the distribution are normal.

Multivariable analysis was performed by selecting variables with $\mathrm{p}<0.05$ in the univariate analysis as potential predictors as well as changing included continuous variables into categorical variables. Logistic regression was applied to assess the OR and 95\% CIs of fetal loss for all potential predictors separately and together, adjusting for confounding factors. Then stepwise regression was used $(\mathrm{p}<0.05$ for the forward and $\mathrm{p}<0.10$ for the backward steps), adjusting for confounding factors, to identify those factors that were most predictive of fetal loss in pregnant patients with SLE. ${ }^{26}$

Variables that were significant in the stepwise regression analysis were used to measure the risk of fetal loss in patients with SLE using the equation: 


$$
P=\frac{e^{Y}}{1+e^{Y}}
$$

$Y$ was estimated from the coefficients of variables in the logistic regression analysis. Goodness-of-fit test for the regression model was assessed using the Hosmer-Lemeshow test and Omnibus test, and the area under the receiver-operating characteristics (ROC) curve (AUC) was used to assess the discrimination of the regression model. To assess model overfitting, we used a 10 -fold cross validation. 192627

A risk scoring system was constructed to classify the fetal loss risk of pregnant patients with SLE. This risk score was calculated using the regression coefficient B of each variable in the logistic regression model, using the equation:

$$
\left|\frac{B_{V}}{B_{\min }}\right|=\text { Score }
$$

$\mathrm{B}_{\mathrm{v}}=$ regression coefficient $B$ of each variable.

A cumulative risk score was calculated for every patient. $^{28}$ ROC curves were plotted, with 1-specificity and sensitivity measured along the horizontal and vertical axes, respectively, with all possible cumulative risk scores in all patients used as cut-off points in the prediction of fetal loss in pregnant patients with SLE. Sensitivity, specificity, accuracy, positive predictive value, negative predictive value, positive likelihood ratio and negative likelihood ratio were used to find the best cut-off of the scoring system.

All tests were two-tailed, and $\mathrm{p}<0.05$ was considered statistically significant. All analyses were performed using SPSS V.22.0 and R Studio V.3.4.1.

\section{Ethics statement}

The research protocol used in this study was reviewed and approved by the Ethics Committee of Ren Ji Hospital, Shanghai Jiao Tong University School of Medicine (2017113). As this was a retrospective observational study, the Medical Ethical Committee granted a waiver for informed consent for this study. Approval to obtain clinical data from the database was received from the office of the medical director of the hospital. All patient information was kept confidential.

\section{RESULTS}

\section{Population characteristics}

A total of 338 pregnancies with SLE were included in this analysis. Their baseline characteristics are shown in table 1 . The mean age at conception was $29.5 \pm 4.0$ years (range, 20-40 years), and the mean time between SLE diagnosis and pregnancy was $5.7 \pm 4.3$ years (range, 0-20 years). The frequency of therapeutic abortions ranged from 0 to 2 times, and the frequency of spontaneous abortions ranged from 0 to 7 times. Almost $70 \%$ of the pregnancies with SLE were from urban areas. Of the patients, $291(86.1 \%)$ were nulliparous. With respect to comorbid conditions, only 1 patient had pre-pregnancy diabetes (not shown in the table) and 10 patients had pre-pregnancy hypertension. There were 293 (86.7\%) planned and $45(13.3 \%)$ unplanned pregnancies. The most common SLE clinical manifestations were mucocutaneous lesions, which were identified in $31.4 \%$ of patients. The mean 24 hour-urinary protein level was $1.04 \pm 2.43 \mathrm{~g}$ (range, $0.01-16.69 \mathrm{~g}$ ). Forty-six patients were positive for aPL antibodies. $\mathrm{C}_{3}$ and $\mathrm{C}_{4}$ hypocomplementemia was present in $90(26.6 \%)$ and 60 patients $(17.8 \%)$, respectively.

\section{Fetal outcomes}

A total of 300 live births $(88.8 \%)$ and 38 fetal losses (11.2\%) was recorded. Eighty-six pregnancies (25.4\%) were preterm births, and 68 neonates had LBWs (including 13 full-term births). Among the pregnancies that ended with a fetal loss, $11(28.9 \%)$ were spontaneous abortions, $21(55.3 \%)$ were therapeutic abortions and 6 $(15.8 \%)$ were stillbirths. There were four live births with congenital malformations, of which one had small atrial septal defect, two had renal problems and one had polydactyly. There were no neonatal deaths (online supplementary table S1).

\section{Risk factors of fetal loss among SLE pregnancies}

As shown in table 2, unplanned pregnancies, pre-pregnancy hypertension, $\mathrm{C}_{3}$ and $\mathrm{C}_{4}$ hypocomplementemia, renal disorders, haematological disorders, the presence of anti-dsDNA and elevated 24 hour-urinary protein levels were significantly associated with fetal loss in the univariate analysis. To make it easier to apply clinically, the 24 hour-urinary protein variable was classified into a categorical variable based on the available clinical reference. ${ }^{29}$

The association between each potential predictor and the risk of fetal loss was statistically significant. A 24 hour-urinary protein level $\geq 1.0 \mathrm{~g} / 24$ hours had the highest OR at 14.85 (95\% CI 6.25 to 35.31 ), followed by $\mathrm{C}_{3}$ hypocomplementemia (OR 11.43, 95\% CI 5.15 to 25.33). When all potential predictors were included in the model, only 24 hour-urinary protein $\geq 1.0 \mathrm{~g} / 24$ hours and $\mathrm{C}_{3}$ hypocomplementemia remained statistically significant. This was likely because of the relatively high correlation between potential predictors. A Spearman correlation was performed, and the result is shown in online supplementary table S2. Using a stepwise regression, unplanned pregnancy status (OR 2.84, 95\% CI 1.12 to 7.22 ), $\mathrm{C}_{3}$ hypocomplementemia (OR 5.46, 95\% CI 2.30 to 12.97) and 24 hour-urinary protein level $(0.3 \leq$ protein $<1.0 \mathrm{~g} / 24$ hours: OR 2.10, $95 \%$ CI 0.63 to 6.95 ; protein $\geq 1.0 \mathrm{~g} / 24$ hours: OR $5.89,95 \%$ CI 2.30 to 15.06 ) were selected for further analysis.

\section{The prediction model and risk score for fetal loss among pregnancies with SLE}

Table 3 shows the $\mathrm{B}$ regression coefficient estimate in the multivariable analysis model. Using the method described above, the result of the Hosmer-Lemeshow test was 
Table 1 Patients' characteristics during pregnancy

\begin{tabular}{|c|c|c|c|c|}
\hline Variables & $\begin{array}{l}\text { Total } \\
\mathrm{n}=338(\%)\end{array}$ & $\begin{array}{l}\text { Live birth } \\
\mathrm{n}=300(\%)\end{array}$ & $\begin{array}{l}\text { Fetal loss } \\
\mathrm{n}=38(\%)\end{array}$ & $P$ value \\
\hline \multicolumn{5}{|l|}{ Characteristics } \\
\hline Age (year, mean \pm SD) & $29.5 \pm 4.0$ & $29.7 \pm 3.9$ & $28.6 \pm 4.5$ & 0.131 \\
\hline History of SLE (year, mean \pm SD) & $5.7 \pm 4.3$ & $5.8 \pm 4.4$ & $4.5 \pm 4.1$ & 0.091 \\
\hline $\begin{array}{l}\text { History of therapeutic abortion } \\
\text { (frequency, mean } \pm S D \text {, range) }\end{array}$ & $\begin{array}{l}0.04 \pm 0.2 \\
(0-2)\end{array}$ & $\begin{array}{l}0.04 \pm 0.2 \\
(0-1)\end{array}$ & $\begin{array}{l}0.08 \pm 0.4 \\
(0-2)\end{array}$ & 0.657 \\
\hline $\begin{array}{l}\text { History of spontaneous abortion (frequency, mean } \pm S D \text {, } \\
\text { range) }\end{array}$ & $\begin{array}{l}0.4 \pm 0.9 \\
(0-7)\end{array}$ & $\begin{array}{l}0.4 \pm 1.0 \\
(0-7)\end{array}$ & $\begin{array}{l}0.3 \pm 0.6 \\
(0-7)\end{array}$ & 0.687 \\
\hline \multicolumn{5}{|l|}{ Region } \\
\hline City & $237(70.1)$ & $210(70.0)$ & $27(71.1)$ & 0.894 \\
\hline Rural & $101(29.9)$ & $90(30.0)$ & $11(28.9)$ & \\
\hline Nullipara & $291(86.1)$ & $258(86.0)$ & $33(86.8)$ & 0.888 \\
\hline Pre-pregnancy hypertension & $10(3.0)$ & $6(2.0)$ & $4(10.5)$ & $0.016^{*}$ \\
\hline Unplanned pregnancy & $45(13.3)$ & $32(10.7)$ & $13(34.2)$ & $<0.001^{*}$ \\
\hline \multicolumn{5}{|l|}{ SLE clinical features } \\
\hline Renal disorder & $97(28.7)$ & $76(25.3)$ & $21(55.3)$ & $<0.001^{*}$ \\
\hline Mucocutaneous & $106(31.4)$ & 94 (31.3) & $12(31.6)$ & 0.975 \\
\hline Haematological disorder & $66(19.5)$ & $53(17.7)$ & $13(34.2)$ & $0.015^{\star}$ \\
\hline Neurological disorder & $5(1.5)$ & $3(1.0)$ & $2(5.3)$ & 0.181 \\
\hline Arthritis & $70(20.7)$ & $63(21.0)$ & $7(18.4)$ & 0.712 \\
\hline Serositis & $17(5.0)$ & $10(3.3)$ & $7(18.4)$ & $0.001^{*}$ \\
\hline \multicolumn{5}{|l|}{ Laboratory features during pregnancy } \\
\hline 24 hour-urinary protein (g, mean $\pm S D$ ) & $1.04 \pm 2.43$ & $0.6 \pm 1.5$ & $4.3 \pm 4.9$ & $<0.001^{*}$ \\
\hline Anti-dsDNA & $261(77.2)$ & $226(75.3)$ & $35(92.1)$ & $0.020^{\star}$ \\
\hline Anti-Ro/SSA & $150(44.4)$ & $132(44.0)$ & $18(47.4)$ & 0.694 \\
\hline Anti-La/SSB & $47(13.9)$ & $41(13.7)$ & $6(15.8)$ & 0.722 \\
\hline Anti-Sm & $20(5.9)$ & $16(5.3)$ & $4(10.5)$ & 0.361 \\
\hline $\mathrm{aPL}$ & $46(13.6)$ & $38(12.7)$ & $8(21.1)$ & 0.156 \\
\hline hypocomplementemia- $\mathrm{C}_{3}$ & $90(26.6)$ & $62(20.7)$ & $28(73.7)$ & $<0.001^{*}$ \\
\hline hypocomplementemia- $\mathrm{C}_{4}$ & $60(17.8)$ & $45(15.0)$ & $15(39.5)$ & $<0.001^{*}$ \\
\hline
\end{tabular}

${ }^{*} \mathrm{P}<0.05$.

SLE, systemic lupus erythematosus.

$\mathrm{p}=0.325\left(\chi^{2}=4.652, \mathrm{df}=4\right)$ and Omnibus test was $\mathrm{p}<0.001$ $\left(\chi^{2}=66.255, \mathrm{df}=4\right)$, which indicated that the logistic regression model had a good fit. The AUC was 0.829 (95\% CI 0.744 to $0.914, \mathrm{SE}=0.043, \mathrm{p}<0.01)$, which indicated that the model has good discrimination (figure 1). The 10-fold cross-validation for this model was $90.0 \%$ accurate.

The fetal loss risk score was calculated using the following equation:

Fetal loss risk score $=$ 'Unplanned pregnancy' SCORE +'hypocomplementemia-C,' SCORE + '24 hour-Urinary protein' SCORE

Figure 2 shows the cumulative risk score and the associated risk of fetal loss in pregnant patients with SLE. As shown in the figure, the fetal loss rate generally increased when the risk score rose.
ROC curve coordinates and potential cut-offs for the risk score system were estimated using a detailed process shown in online supplementary tables S3-S6.

A score of 3 was the best cut-off point (sensitivity $=60.5 \%$, specificity $=93.3 \%$, accuracy $=89.6 \%$, positive predictive value $=53.5 \%$, negative predictive value $=94.9 \%$, positive likelihood ratio $=9.03$, and negative likelihood ratio $=0.42$ ). The risk classification for fetal loss according to the risk score system is shown on table 4 .

For example, a pregnant woman with SLE who went to antenatal care at 18 weeks was diagnosed with new-onset SLE during pregnancy (1), had a lower $\mathrm{C}_{3}$ complement level (2) and had a 24 hour-urinary protein of $0.8 \mathrm{~g} / 24$ hours (1) would have a cumulative risk score of 4 , which belongs in the high risk for fetal loss group. 
Table 2 Multivariable analysis of fetal loss

\begin{tabular}{|c|c|c|c|}
\hline \multirow[b]{2}{*}{ Variables } & $\begin{array}{l}\text { Risk factors included } \\
\text { individually }\end{array}$ & $\begin{array}{l}\text { Risk factors included } \\
\text { simultaneously }\end{array}$ & $\begin{array}{l}\text { Risk F actors selected } \\
\text { using stepwise } \\
\text { regression }\end{array}$ \\
\hline & OR (95\% Cl) & OR $(95 \% \mathrm{Cl})$ & OR $(95 \% \mathrm{Cl})$ \\
\hline Unplanned pregnancy & $4.33(1.71 \text { to } 11.00)^{\star \star}$ & 3.01 (0.90 to 10.02$)$ & $2.84(1.12 \text { to } 7.22)^{\star}$ \\
\hline Pre-pregnancy hypertension & $6.45(1.60 \text { to } 26.06)^{\star \star}$ & $5.24(0.74$ to 37.38$)$ & - \\
\hline hypocomplementemia- $\mathrm{C}_{3}$ & $11.43(5.15 \text { to } 25.33)^{\star *}$ & $7.09(2.60 \text { to } 19.36)^{\star \star}$ & $5.46(2.30 \text { to } 12.97)^{\star \star}$ \\
\hline Renal disorder & $3.58(1.76 \text { to } 7.28)^{\star \star}$ & 0.33 (0.09 to 1.15$)$ & - \\
\hline Haematological disorder & $2.19(1.02 \text { to } 4.69)^{\star}$ & 0.90 (0.32 to 2.53$)$ & - \\
\hline Anti-dsDNA & $3.62(1.07 \text { to } 12.17)^{\star}$ & 2.58 (0.65 to 10.24$)$ & - \\
\hline \multicolumn{4}{|l|}{24 hour-urinary protein } \\
\hline
\end{tabular}

${ }^{*} \mathrm{P}<0.05$; ${ }^{*} \mathrm{P}<0.01$; Multivariable models adjusted for age at conception (continuous), history of SLE (continuous), history of therapeutic abortion (continuous), history of spontaneous abortion (continuous), region (city vs rural), nullipara (nullipara vs multipara).

SLE, systemic lupus erythematosus .

\section{DISCUSSION}

\section{Principal findings of the study}

In this study, we showed that pregnant women with SLE have a high risk of adverse fetal outcomes, including fetal loss, preterm births and LBWs. Unplanned pregnancies, hypocomplementemia $\mathrm{C}_{3}$ and an elevated 24 hour-urinary protein level were independent risk factors for fetal loss after adjusting for possible confounders. Patients can be classified into different risk groups based on the values of these three variables, which may help obstetricians and rheumatologists predict pregnancy outcomes.

\section{Comparison with previous studies}

Significant progress has been made in the study and antenatal care monitoring of pregnancies complicated with

Table 3 Adjusted OR and B coefficient from cohort with multivariable logistic regression model and corresponding risk score

\begin{tabular}{|c|c|c|c|}
\hline Variables & $\begin{array}{l}\text { Adjusted } \\
\text { OR }\end{array}$ & B & Score \\
\hline \multicolumn{4}{|l|}{ Unplanned pregnancy } \\
\hline Planned pregnancy & 1 & & 0 \\
\hline Unplanned pregnancy & 2.84 & 1.04 & 1 \\
\hline \multicolumn{4}{|l|}{ hypocomplementemia- $\mathrm{C}_{3}$} \\
\hline Non-hypocomplementemia- $\mathrm{C}_{3}$ & 1 & & 0 \\
\hline hypocomplementemia- $\mathrm{C}_{3}$ & 5.46 & 1.70 & 2 \\
\hline \multicolumn{4}{|l|}{24 hour-urinary protein } \\
\hline Urinary protein $<0.3 \mathrm{~g} / 24$ hours & 1 & & 0 \\
\hline $\begin{array}{l}0.3 \leq \text { Urinary } \\
\text { protein }<1.0 \mathrm{~g} / 24 \text { hours }\end{array}$ & 2.10 & 0.74 & 1 \\
\hline Urinary protein $\geq 1.0 \mathrm{~g} / 24$ hours & 5.89 & 1.77 & 2 \\
\hline
\end{tabular}

SLE. In recent decades, most women with SLE can have a more favourable pregnancy outcome. ${ }^{68}$ However, fetal loss and other adverse fetal outcomes remain common in the SLE population. ${ }^{30-32}$

Fetal loss rates have ranged from $3 \%$ to $43 \%$ in prior studies. 8101113143133 Our total fetal loss rate was $11.2 \%$, which falls at the lower end of what was reported in the literature. Two other recent Chinese studies reported

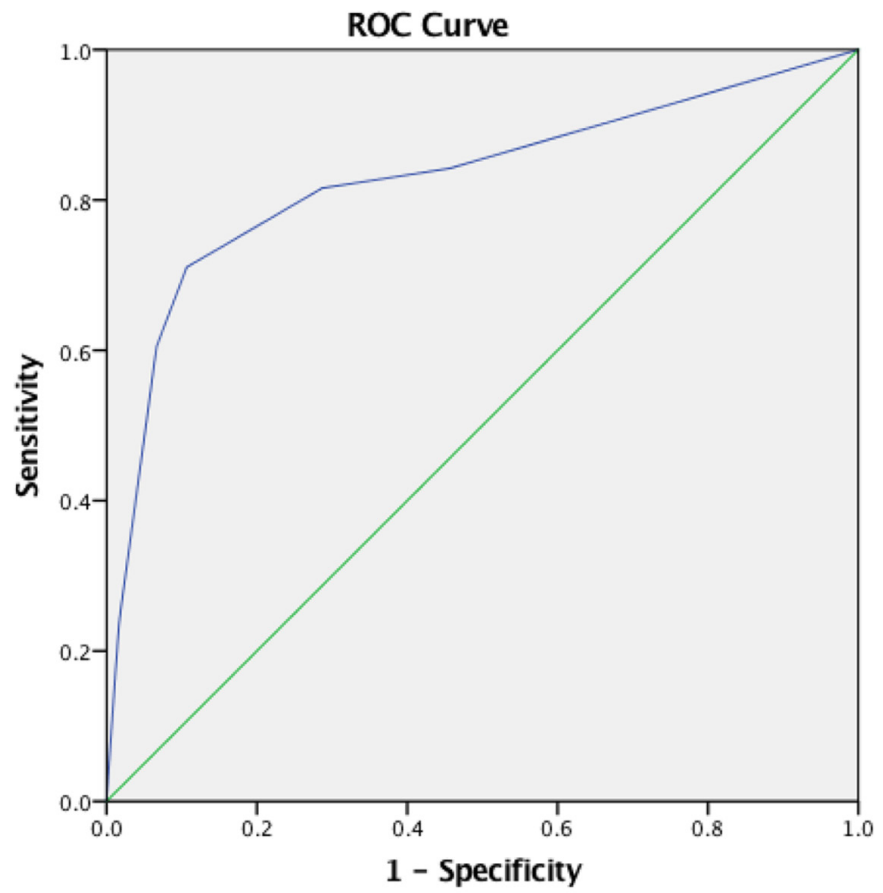

Diagonal segments are produced by ties.

Figure 1 ROC curve of the prediction model. ROC, receiveroperating characteristic. 


\section{Score - morbidity of fetal loss}

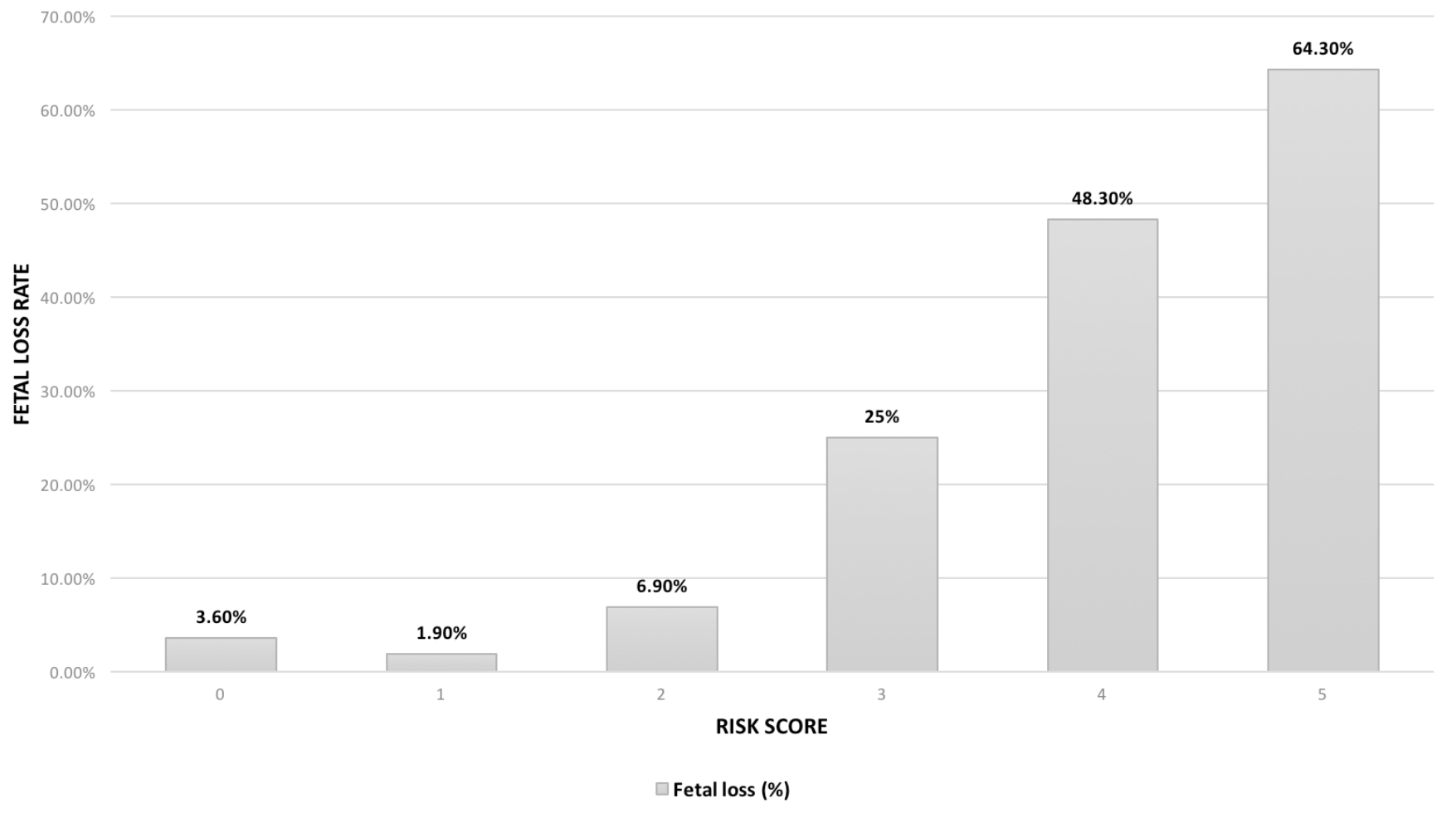

Figure 2 Fetal loss risk in pregnant patients with SLE based on their cumulative risk score. SLE, systemic lupus erythematosus.

a relatively low rate of fetal loss. ${ }^{10}{ }^{13}$ Whether Chinese patients with SLE have a lower fetal loss rate than those from other ethnicities requires further study.

Our data showed that in the univariate analysis, unplanned pregnancies, hypocomplementemia $\mathrm{C}_{3}$ and 24 hour-urinary protein levels improved our outcome predictions better than other variables and were selected by stepwise regression models. These three variables were stronger predictors of the overall risk of fetal loss. Clowse et al reported that regardless of SLE activity, low complement levels during the second trimester were associated with a higher rate of pregnancy loss and preterm births. ${ }^{9}$ Few studies observed an association between fetal loss and 24 hour-urinary protein level, which is a very easy and practical laboratory test to perform. Our study first compared 24 hour-urinary protein level as a continuous variable and found it to be significantly higher in fetal loss group.

Table 4 The risk classification for fetal loss according to the risk score system

\begin{tabular}{lrlll}
\hline Risk & N & $\%$ & $\begin{array}{l}\text { Fetal } \\
\text { loss (N) }\end{array}$ & $\begin{array}{l}\text { Fetal } \\
\text { loss (\%) }\end{array}$ \\
\hline Low risk (0-3) & 295 & 87.3 & 15 & 5.1 \\
High risk (>3) & 43 & 12.7 & 23 & 53.5 \\
Total & 338 & 100 & 38 & 11.2 \\
\hline
\end{tabular}

$\mathrm{P}<0.01$.
When performing the multivariable analysis and developing our risk score, we converted 24 hour-urinary protein level into a categorical variable based on clinical practice, which was as follows: urinary protein $<0.3 \mathrm{~g} / 24$ hours; $0.3 \leq$ urinary protein $<1.0 \mathrm{~g} / 24$ hours; urinary protein $\geq 1.0 \mathrm{~g} / 24$ hours. ${ }^{29}$ The presence of urinary protein $\geq 1.0 \mathrm{~g} / 24$ hours was a strong predictor of fetal loss, even in our multivariable analysis. Other studies reported that the presence of active lupus nephritis increased the risk of fetal loss. ${ }^{561134}$ However, few studies failed to observe an association between lupus nephritis and fetal loss. ${ }^{10} 1435$ A Chinese retrospective study of 111 pregnant patients with SLE found that proteinuria was a predictor for fetal loss in a univariate analysis, but was not associated with fetal loss in a multivariable analysis, ${ }^{13}$ a finding that may be due to the small sample size.

SLE activity during pregnancy is a well-known risk factor for a poor fetal outcome. Teh et al found that SLE flares contributed to $60.0 \%$ of fetal losses in Malaysia. ${ }^{12}$ Zhan et $a l$ also reported that patients with active lupus had a 12.4fold higher risk of fetal loss in a retrospective study of 263 pregnant patients with SLE. ${ }^{8} \mathrm{Ku}$ et al found that patients with new-onset SLE during pregnancy had a significantly higher rate of fetal loss $(73.7 \%$ vs $15.6 \%, \mathrm{p}<0.01) .{ }^{14}$ Lateef et al suggested that optimal disease control for at least 6 months prior to conception should be ensured to reduce the risk of fetal loss. ${ }^{36}$ In our study, we divided patients into planned and unplanned pregnancy groups based 
on conception timing, which we believe to be easier and more practical for clinicians to use. Our results were consistent with those of previous studies.

Several studies focused on the risk factors for fetal loss in pregnant patients with SLE in different settings. For example, Al Arfaj et al found that lupus nephritis $(\mathrm{OR}=7.3)$, aPL antibodies (OR=3.9), and SLE flares during pregnancy $(\mathrm{OR}=1.9)$ were predictors of fetal loss. ${ }^{11}$ Clowse et al reported that live birth rates were strongly affected by high lupus activity. ${ }^{37}$ In 2016 , Tian et al studied 2026 Chinese pregnant women with SLE and found that aPL, anti-SSA antibodies and thrombocytopaenia were associated with fetal loss, and arthritis was associated with a favourable fetal outcome. ${ }^{10}$ However, very few studies attempted to establish a risk score classification. Here, we developed a prediction model with a risk score classification that is simple to use and has predictors that are very easy to obtain clinically. Paydar et al developed a clinical decision support system to help physicians predict pregnancy outcomes in women with SLE. It was well-developed and had a high predictive accuracy. However, it included 16 variables and required specific software that was not easy for clinicians to obtain. ${ }^{19}$

\section{Strengths and limitations}

The present study is noteworthy for several reasons. While other studies have reported on the risk factors for fetal loss in pregnant patients with SLE, to our knowledge, no other study has developed a prediction model and risk score classification for SLE fetal loss, which is one of the most important fetal outcomes in pregnancies of mothers with SLE. Additionally, the present study included a relatively large sample size. Further, our prediction model has a good fit and discrimination, as does the risk score classification, indicating a higher predictive value. Finally, the risk score classification is clinically practical, as the model is simple and the included variables are routinely collected during the first antenatal care visit. ${ }^{27}$

Nevertheless, our study has some limitations. First, as there are limited pregnancies in patients with SLE, the development and validation process of this model has to apply to the same cohort. Although 10-fold cross-validation was performed and had a good result, it still cannot assess the generalisability of this model. It would be better to have an external validation in the future. ${ }^{38}$ Second, as a retrospective study, this study has inherent information bias. Finally, clinical records lacked additional details regarding baseline population characteristics, such as education level, body mass index, family income and so on. These factors may be confounders in this study.

\section{Future direction}

In future, a prospective study will be conducted and more patients will be recruited for further analysis to validate this predictive model. Moreover, since pregnancy is a 10-month process, the relationship between pregnancy outcome and the trend of laboratory parameters rather than a single time point result need to be further explored. Finally, the effects and safety of different kinds of medicine will be further observed and elucidated in pregnant women with SLE.

\section{CONCLUSION}

The predictive model proposed in this study permits a quick and high quality estimate of the risk of fetal loss among pregnancies with SLE at their first antenatal care visit $(16 \mathrm{~W}-20 \mathrm{~W})$, which is an essential step in SLE antenatal care. Identifying a high-risk group, strengthening monitoring or/and intervening at an early gestational stage may potentially improve fetal outcomes.

\section{Author affiliations \\ ${ }^{1}$ Department of Obstetrics and Gynecology, Ren Ji Hospital, School of Medicine, Shanghai Jiao Tong University, Shanghai, China \\ ${ }^{2}$ Shanghai Key Laboratory of Gynecologic Oncology, Shanghai, China \\ ${ }^{3}$ International Centre for Reproductive Health (ICRH), Ghent University, Gent, Belgium ${ }^{4}$ Research Laboratory for Human Reproduction, Université Libre de Bruxelles (ULB), Brussels, Belgium \\ ${ }^{5}$ Department of Rheumatology, Ren Ji Hospital, School of Medicine, Shanghai Jiao Tong University, Shanghai, China \\ ${ }^{6}$ Shanghai Institute of Rheumatology, Shanghai, China \\ ${ }^{7}$ School of Public Policy and Administration, Xi'an Jiaotong University, Xi'an, China}

Acknowledgements Not applicable

Contributors JW, JM, CB, JL, W-HZ and WD were each responsible for the conception and design of the study. JW, JM and WD had full access to all of the data in the study. JW and JM collected the data. JW, JM, JL and W-HZ analysed and interpreted the data. JW drafted the initial manuscript. W-HZ., CB, JL and WD revised the manuscript. All authors read and approved the final version of the manuscript.

Funding The work was supported by funding from Shanghai Municipal Commission of Health and Family Planning (Grant nos. $2017 Z Z 202016$ and 15GWZK0701).

Competing interests None declared.

Patient consent for publication Not required.

Provenance and peer review Not commissioned; externally peer reviewed. Data sharing statement No additional data available.

Open access This is an open access article distributed in accordance with the Creative Commons Attribution Non Commercial (CC BY-NC 4.0) license, which permits others to distribute, remix, adapt, build upon this work non-commercially, and license their derivative works on different terms, provided the original work is properly cited, appropriate credit is given, any changes made indicated, and the use is non-commercial. See: http://creativecommons.org/licenses/by-nc/4.0/.

\section{REFERENCES}

1. Meyer O. Making pregnancy safer for patients with lupus. Joint Bone Spine 2004;71:178-82.

2. Clowse ME, Grotegut C. Racial and ethnic disparities in the pregnancies of women with systemic lupus erythematosus. Arthritis Care Res 2016;68:1567-72.

3. Lateef A, Petri M. Systemic lupus erythematosus and pregnancy. Rheum Dis Clin North Am 2017;43:215-26.

4. Buyon JP, Kim MY, Guerra MM, et al. Predictors of pregnancy outcomes in patients with lupus: a cohort study. Ann Intern Med 2015;163:153-63.

5. Wagner SJ, Craici I, Reed D, et al. Maternal and foetal outcomes in pregnant patients with active lupus nephritis. Lupus 2009;18:342-7.

6. Moroni G, Quaglini S, Banfi G, et al. Pregnancy in lupus nephritis. Am J Kidney Dis 2002;40:713-20.

7. Wu J, Ma J, Zhang WH, et al. Management and outcomes of pregnancy with or without lupus nephritis: a systematic review and meta-analysis. Ther Clin Risk Manag 2018;14:885-901. 
8. Zhan Z, Yang Y, Zhan Y, et al. Fetal outcomes and associated factors of adverse outcomes of pregnancy in southern Chinese women with systemic lupus erythematosus. PLoS One 2017;12:e0176457.

9. Clowse ME, Magder LS, Petri M. The clinical utility of measuring complement and anti-dsDNA antibodies during pregnancy in patients with systemic lupus erythematosus. J Rheumatol 2011;38:1012-6.

10. Tian X, Li M, Ye Z, et al. Related factors of fetal loss in Chinese women with systemic lupus erythematosus: data from Chinese SLE Treatment and Research Group registry IV. Int J Rheum Dis 2015:18:654-60.

11. Al Arfaj AS, Khalil N. Pregnancy outcome in 396 pregnancies in patients with SLE in Saudi Arabia. Lupus 2010;19:1665-73.

12. Teh CL, Wong JS, Ngeh NK, et al. Systemic lupus erythematosus pregnancies: the Sarawak experience and review of lupus pregnancies in Asia. Rheumatol Int 2011;31:1153-7.

13. Liu J, Zhao Y, Song Y, et al. Pregnancy in women with systemic lupus erythematosus: a retrospective study of 111 pregnancies in Chinese women. J Matern Fetal Neonatal Med 2012;25:261-6.

14. Ku M, Guo S, Shang W, et al. Pregnancy outcomes in chinese patients with systemic lupus erythematosus (sle): a retrospective study of 109 pregnancies. PLOS One 2016;11:e0159364.

15. Yerlikaya G, Akolekar R, McPherson K, et al. Prediction of stillbirth from maternal demographic and pregnancy characteristics. Ultrasound Obstet Gynecol 2016;48:607-12.

16. Teh CL, Wan SA, Cheong YK, et al. Systemic lupus erythematosus pregnancies: ten-year data from a single centre in Malaysia. Lupus 2017;26:218-23.

17. Vinet E, Labrecque J, Pineau CA, et al. A population-based assessment of live births in women with systemic lupus erythematosus. Ann Rheum Dis 2012;71:557-9.

18. Trudell AS, Tuuli MG, Colditz GA, et al. A stillbirth calculator: Development and internal validation of a clinical prediction model to quantify stillbirth risk. PLoS One 2017;12:e0173461.

19. Paydar K, Niakan Kalhori SR, Akbarian M, et al. A clinical decision support system for prediction of pregnancy outcome in pregnant women with systemic lupus erythematosus. Int $J$ Med Inform 2017:97:239-46.

20. Hochberg MC. Updating the American College of Rheumatology revised criteria for the classification of systemic lupus erythematosus. Arthritis Rheum 1997;40:1725.

21. Gladman DD, Ibañez D, Urowitz MB. Systemic lupus erythematosus disease activity index 2000. J Rheumatol 2002;29:288-91.

22. WHO. Aspects of low birth weight. Report of the expert committee of maternal child health. WHO Technical Report 1961;217:3-16.

23. Ruperto N, Hanrahan LM, Alarcón GS, et al. International consensus for a definition of disease flare in lupus. Lupus 2011;20:453-62.
24. Tavares Da Silva F, Gonik B, McMillan M, et al. Stillbirth: Case definition and guidelines for data collection, analysis, and presentation of maternal immunization safety data. Vaccine 2016;34:6057-68.

25. Jehan I, Harris H, Salat S, et al. Neonatal mortality, risk factors and causes: a prospective population-based cohort study in urban Pakistan. Bull World Health Organ 2009;87:130-8.

26. Tworoger SS, Zhang $\mathrm{X}$, Eliassen $\mathrm{AH}$, et al. Inclusion of endogenous hormone levels in risk prediction models of postmenopausal breast cancer. J Clin Oncol 2014;32:3111-7.

27. Royston P, Moons KG, Altman DG, et al. Prognosis and prognostic research: Developing a prognostic model. BMJ 2009;338:b604.

28. Yang HI, Yuen MF, Chan HL, et al. Risk estimation for hepatocellular carcinoma in chronic hepatitis B (REACH-B): development and validation of a predictive score. Lancet Oncol 2011;12:568-74.

29. Piccoli GB, Cabiddu G, Attini R, et al. Risk of adverse pregnancy outcomes in women with CKD. J Am Soc Nephrol 2015;26:2011-22.

30. Clowse ME, Jamison M, Myers E, et al. A national study of the complications of lupus in pregnancy. Am J Obstet Gynecol 2008;199:127.e1-127.e6.

31. Jakobsen IM, Helmig RB, Stengaard-Pedersen K. Maternal and foetal outcomes in pregnant systemic lupus erythematosus patients: an incident cohort from a stable referral population followed during 1990-2010. Scand J Rheumatol 2015;44:85.

32. Chen $\mathrm{CY}$, Chen YH, Lin HC, et al. Increased risk of adverse pregnancy outcomes for hospitalisation of women with lupus during pregnancy: a nationwide population-based study. Clin Exp Rheumatol 2010;28:49-55.

33. Molokhia M, Maconochie N, Patrick AL, et al. Cross-sectional analysis of adverse outcomes in 1,029 pregnancies of AfroCaribbean women in Trinidad with and without systemic lupus erythematosus. Arthritis Res Ther 2007;9:R124.

34. Lv J, Wang W, Li Y. Clinical outcomes and predictors of fetal and maternal consequences of pregnancy in lupus nephritis patients. Int Urol Nephrol 2015;47:1379-85.

35. Gladman DD, Tandon A, Ibañez D, et al. The effect of lupus nephritis on pregnancy outcome and fetal and maternal complications. $J$ Rheumatol 2010;37:754-8.

36. Lateef A, Petri M. Managing lupus patients during pregnancy. Best Pract Res Clin Rheumatol 2013;27:435-47.

37. Clowse ME, Magder LS, Witter F, et al. The impact of increased lupus activity on obstetric outcomes. Arthritis Rheum 2005;52:514-21.

38. Altman DG, Vergouwe $\mathrm{Y}$, Royston $\mathrm{P}$, et al. Prognosis and prognostic research: validating a prognostic model. BMJ 2009;338:b605. 